\title{
Transthoracic needle biopsy in the diagnosis of solitary pulmonary nodules: A survey of Canadian physicians
}

Yves Lacasse, MD, MSc

Julie Plante, MD

Simon Martel, MD

Bruno Raby, MD, MSc

From the Centre de recherche, Hôpital Laval, Institut universitaire de cardiologie et de pneumologie de l'Université Laval, SteFoy, Québec, Canada.

Supported by the Fondation J. D. Bégin, Université Laval, Ste-Foy, Québec, Canada. Yves Lacasse is a clinician scientist of the Fonds de la recherche en santé du Québec

Received for publication Dec 4, 2001; revisions requested March 28, 2002; revisions received Oct 7, 2002; accepted for publication Oct 18, 2002.

Address for reprints: Yves Lacasse, Hôpital Laval, Centre de Pneumologie, 2725 Chemin Ste-Foy, Ste-Foy, Québec G1V 4G5, Canada (E-mail: yves.lacasse@med.ulaval. ca).

J Thorac Cardiovasc Surg 2003;126:761-8

Copyright (๑) 2003 by The American Association for Thoracic Surgery

$0022-5223 / 2003 \$ 30.00+0$

doi:10.1016/S0022-5223(03)00043-6
Objective: To describe Canadian physicians' opinions relative to the choice of diagnostic procedures in patients presenting with a solitary pulmonary nodule and to identify the attributes that may influence their decision.

Methods: We conducted a mailed survey among Canadian physicians including pulmonologists, thoracic surgeons, radiologists, and internists. Five hypothetical clinical scenarios designed to illustrate a wide spectrum of clinical situations (including nodules associated to very low, indeterminate, and high probabilities of malignancy in patients medically fit or unfit to undergo surgical resection) were submitted to each physician who had to choose among options of diagnostic procedures and to estimate the pretest probability of malignancy.

Results: The survey response rate was $47 \%$. Overall, the physicians tended to overestimate the probability of malignancy. Twenty-eight percent of the respondents would have ordered a transthoracic needle biopsy in a medically fit patient presenting with a very low probability $(<2 \%)$ of malignancy, whereas $53 \%$ would have done so in a medically fit patient presenting with a very high probability $(75 \%)$ of malignancy. In a regression analysis, the significant predictors of the use of transthoracic needle biopsy were (1) the pretest probability of cancer, (2) the patient's operability, (3) specialty (pulmonologists and thoracic surgeons being less likely to order a transthoracic needle biopsy than radiologists), and (4) the respondent's gender.

Conclusions: There are widespread variations in clinical opinions among Canadian physicians regarding the use of transthoracic needle biopsy in the investigation of solitary nodules. Hypothetical transthoracic needle biopsy was often preferred when the result was unlikely to affect patient management.

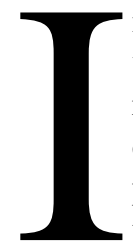
n 1995, American physicians investigated an estimated 150,000 patients with pulmonary nodules. ${ }^{1}$ Most often, their primary goal was to establish or reject a diagnosis of malignancy. As many as $10 \%$ to $20 \%$ of bronchogenic carcinomas initially appear as solitary pulmonary nodules. ${ }^{2}$ Causes of pulmonary nodules are, nevertheless, multiple and the proportion of lesions that prove benign varies widely in the published series. Although an array of clinical characteristics may help predict the malignant or benign nature of a pulmonary nodule, ${ }^{1,3,4}$ the final diagnosis most often relies on histopathology.

Transthoracic needle biopsy (TNB) is a diagnostic technique that provides histologic or cytologic material from lung lesions. ${ }^{5}$ Guidelines regarding the indications of TNB remain nondirective, and the American Thoracic Society recommends that "experience and sound clinical judgment. . .determine its use in individual cases." Reappraisal of the use of TNB in the diagnosis of localized pulmonary lesions requires a better understanding of its accuracy and clarification regarding its indications. A recent meta-analysis ${ }^{7}$ of the diagnostic accuracy of TNB 
indicated that it provides definitive results only when findings of "malignant" or of a specific diagnosis of a benign condition provide definitive results. Findings of "suspicious" markedly increases probability of malignancy, and "benign" markedly decreases it, but may not be considered definitive. Nevertheless, biopsies are often performed routinely, regardless of the probability of malignancy, when it is unclear that the biopsy will modify the clinical management of the patient. ${ }^{8,9}$

The objective of this study was to identify what determines physicians' choices of diagnostic procedures in patients presenting with a solitary pulmonary nodule. More specifically, we sought to (1) describe Canadian physicians' current opinions relative to the choice of diagnostic procedures in patients with a solitary pulmonary nodule; (2) identify the attributes (including physicians' training, clinical practice, and appointment) that may influence their decision; and (3) examine whether the physicians' estimate of the probability of malignancy modulates the choice of diagnostic procedure in patients with a solitary pulmonary nodule. To do so, we conducted a national survey among Canadian physicians most likely to be involved in the management of patients with a solitary pulmonary nodule. We hypothesized that the estimated pretest probability of malignancy would determine the decision to perform a TNB and that physicians' attributes (especially their specialty) would predict their use of TNB.

\section{Methods \\ Study Population}

Pulmonologists, thoracic surgeons, radiologists, and internists were surveyed. We selected physicians from the 1999 Canadian Medical Directory. A total of 4778 potentially eligible physicians were identified. The sample included physicians from each province in proportion to their number in the target population. The sample population was randomly selected from the target population (stratified random sampling).

\section{Survey}

The first section of the survey was designed to collect general information on respondents including gender, year of graduation, specialty, clinical experience with the investigation of solitary pulmonary nodules, and work environment (university affiliated or not). Each respondent was then presented with 5 hypothetical clinical scenarios that were designed to illustrate a wide spectrum of situations currently encountered in clinical practice (see appendix), including benign, indeterminate, or malignant nodules in patients medically fit or unfit to undergo surgical resection. Each case was designed to correspond to a pretest probability of malignancy that was determined from a set of clinical and radiologic characteristics and from a clinical prediction model recently published by Swensen and coworkers. ${ }^{1}$ For each scenario, physicians had to choose among options of diagnostic procedures and to estimate the probability of malignancy from a 100-mm (0\%-100\%) analog scale.
The survey was conducted between March and May 2000 according to the total design method described by Dillman. ${ }^{10}$ Each physician in the sample was mailed a package containing a cover letter signed by the investigators, a booklet of questions in his/her language (French or English), and a stamped, addressed reply envelope. Each survey was numbered and coded for identification and to protect confidentiality. One week later, this first mailing was followed by a reminder postcard. Six weeks later, those who had not responded to the initial survey were sent a second package that was identical to the first one except for the cover letter, which mentioned that their survey had not yet been received.

\section{Statistics}

Sample size. In calculating the sample size needed for this study, we hypothesized that patients in whom the biopsy was truly indicated (ie, in our opinion, the patient with intermediate pretest probability of malignancy who was medically fit for surgery) would be at least twice as likely to undergo a biopsy as those in whom the indication of biopsy was not clear. We anticipated that $25 \%$ of those patients in whom the biopsy was not clearly indicated would actually undergo a biopsy. Given the large number of planned statistical comparisons, the level of statistical significance in the regression analyses was set at the .01 level. Study power was set at $85 \%$. From these specifications, we calculated that 500 responses were needed. This sample size was augmented to take into account the anticipated response rate that was likely to vary according to the subspecialties. The highest response rate was expected from pulmonologists and the lowest from internists. Also, we anticipated a low response rate from the thoracic surgeons since most of them are classified in the Canadian Medical Directory as cardiothoracic surgeons. Given the small number of cardiothoracic surgeons, $100 \%$ of them were surveyed to obtain a reasonable number of responses. Accordingly, a total of 1470 physicians were surveyed: 458 radiologists, 455 internists, 320 pulmonologists, and 237 surgeons.

Response rate. The response rate was calculated as the ratio of analyzable responses over the number of eligible physicians that were reached. ${ }^{11}$

Response rate $=\frac{\text { Number of analyzable questionnaires }}{\text { Number in sample }-(\text { Noneligible }+ \text { Nonreachable })}$

A "noneligible" designation was applied to physicians who returned their survey indicating that they are never called to evaluate patients with a solitary pulmonary nodule in their practice. A "nonreachable" designation was applied to physicians whose first package was returned to us. Newfoundland, Nova Scotia, Prince Edward Island, and New Brunswick were analyzed as the Atlantic provinces and Alberta, Saskatchewan, and Manitoba as the Prairies. The other provinces (Ontario, Québec, and British Columbia) were analyzed separately.

Analysis. Descriptive statistics (proportions, means, and standard deviations when appropriate) were used to characterize the study population. A frequency distribution of the different diagnostic options was computed for each scenario and by specialty. Between-specialty comparisons were conducted using $\chi^{2}$ tests. The estimated pretest probabilities of malignancy were described using the mean ( \pm standard deviation) and compared to the pretest probability derived from Swensen's clinical prediction model us- 


\begin{tabular}{|c|c|c|c|c|c|c|c|}
\hline \multirow[b]{2}{*}{ Clinical scenario } & \multirow[b]{2}{*}{$\begin{array}{c}\text { Probability } \\
\text { (Swensen's } \\
\text { model, \%) }\end{array}$} & \multicolumn{6}{|c|}{ Respondents' estimates of pretest probability of malignancy } \\
\hline & & Overall* & Respirologists & Radiologists & $\begin{array}{l}\text { Thoracic } \\
\text { surgeons }\end{array}$ & Internists & $\begin{array}{c}\text { Comparison } \\
\text { across } \\
\text { specialties } \\
(P \text { value })\end{array}$ \\
\hline \multicolumn{8}{|l|}{ Case 1} \\
\hline $\begin{array}{l}\text { Very high probability, } \\
\text { Medically fit for surgery }\end{array}$ & 75 & $\begin{array}{c}87 \%(10) \\
(P<.0001) \dagger\end{array}$ & $\begin{array}{l}89 \% \\
8\end{array}$ & $\begin{array}{l}88 \% \\
10\end{array}$ & $\begin{array}{c}87 \% \\
9\end{array}$ & $\begin{array}{l}81 \% \\
12\end{array}$ & $<.0001$ \\
\hline Case 2 & & & & & & & \\
\hline $\begin{array}{l}\text { Intermediate probability, } \\
\text { Medically fit for surgery }\end{array}$ & 38 & $\begin{array}{c}59 \%(17) \\
(P<.0001) \dagger\end{array}$ & $\begin{array}{l}60 \% \\
16\end{array}$ & $\begin{array}{l}61 \% \\
18\end{array}$ & $\begin{array}{l}63 \% \\
17\end{array}$ & $\begin{array}{l}51 \% \\
17\end{array}$ & $<.0001$ \\
\hline Case 3 & & & & & & & \\
\hline $\begin{array}{l}\text { Very low probability, } \\
\text { Medically fit for surgery }\end{array}$ & 2 & $\begin{array}{c}22 \%(13) \\
(P<.0001) \dagger\end{array}$ & $\begin{array}{l}19 \% \\
11\end{array}$ & $\begin{array}{l}24 \% \\
15\end{array}$ & $\begin{array}{l}24 \% \\
14\end{array}$ & $\begin{array}{l}22 \% \\
11\end{array}$ & .004 \\
\hline Case 4 & & & & & & & \\
\hline $\begin{array}{l}\text { Very high probability, } \\
\text { Medically unfit for surgery }\end{array}$ & 83 & $\begin{array}{c}87 \%(10) \\
(P<.0001) \dagger\end{array}$ & $\begin{array}{c}89 \% \\
9\end{array}$ & $\begin{array}{l}87 \% \\
11\end{array}$ & $\begin{array}{l}86 \% \\
10\end{array}$ & $\begin{array}{l}83 \% \\
12\end{array}$ & .002 \\
\hline Case 5 & & & & & & & \\
\hline $\begin{array}{l}\text { Intermediate probability, } \\
\text { Medically unfit for surgery }\end{array}$ & 34 & $\begin{array}{c}74 \%(18) \\
(P<.0001) \dagger\end{array}$ & $\begin{array}{l}78 \% \\
15\end{array}$ & $\begin{array}{l}68 \% \\
21\end{array}$ & $\begin{array}{l}77 \% \\
14\end{array}$ & $\begin{array}{l}75 \% \\
15\end{array}$ & .0004 \\
\hline
\end{tabular}

*Mean probability (SD).

tComparison ( $P$ value) with the probability derived from Swensen's model.

ing $t$ tests. Between-specialty comparisons were conducted using analyses of variance.

We conducted a logistic regression analysis to test the hypothesis that some physicians' attributes (including their training, practice, and appointment), their estimate of pretest probability of malignancy, as well as the patient's medical fitness to undergo surgical resection may influence their decision to have a biopsy performed on a patient. Since each physician we surveyed had to examine 5 different case scenarios, the responses provided by an individual physician could not be regarded as independent observations. To correct for this situation, we adopted the method introduced by Liang and Zeger ${ }^{12}$ by constructing a generalized linear model with unstructured covariance. In this model, the physicians' estimates of the pretest probability of malignancy were categorized according to thresholds defining very low $(<5 \%)$, low $(5 \%-30 \%)$, intermediate $(31 \%-50 \%)$, high $(51 \%-70 \%)$, and very high $(>70 \%)$ probabilities of cancer. ${ }^{13}$

\section{Results}

\section{Respondents}

A total of 1470 physicians (31\% of the total sampling frame) were sent the survey and $828(56 \%)$ replied. Of these 828,516 completed the survey and 312 indicated that they were never called to investigate patients with solitary nodules (and were, therefore, considered "noneligible"). Additionally, 54 packages were returned by the post office as undeliverable. Therefore, the response rate among potentially eligible respondents was $516 /(1470-[312+54])$, or $47 \%$.

All the regions of the country were represented, with response rates ranging from $44 \%$ in the Prairies to $50 \%$ in British Columbia. The response rate from the 4 disciplines was heterogeneous: respirology, 62\%; radiologists, 44\%; thoracic surgeons, 36\%; and internists, 20\%. The respondents were unevenly divided by specialty: respirology, 187; radiologists, 167; thoracic surgeons, 81; and internists, 81. Sixteen percent of the respondents were women. On average, the respondents had been in clinical practice for 21 years (SD: 10); 58\% worked in a university-affiliated teaching hospital. Most of them had extensive experience in managing patients with a solitary nodule, as 304 (59\%) claimed that they investigate more than 12 patients a year in such circumstances. Only $141(27 \%)$ of the respondents (mostly radiologists, $\mathrm{n}=120$ ) performed TNB themselves.

\section{Estimates of Pretest Probability of Malignancy}

The pretest probability of malignancy determined from Swensen's clinical prediction model are presented in Table 1. These probabilities are compared with those elicited by the respondents. Overall, the physicians tended to overestimate the probability of malignancy. There were small (although statistically significant) differences in the estimates across specialties.

\section{Patient Management}

Table 2 summarizes the respondents' answer to the following question: "Given this clinical situation, in your current practice, would you order a TNB for this patient?" Of note, more than $50 \%$ of the respondents would have ordered a biopsy on the medically fit patient with a very high probability of cancer (case 1), whereas more than $25 \%$ of them would have done so for the patient with a nodule associated with a very low probability of malignancy (case 3 ). We 
TABLE 2. Proportion of respondents who would have ordered a transthoracic needle biopsy

\begin{tabular}{|c|c|c|c|c|c|c|}
\hline \multirow[b]{2}{*}{ Clinical scenario } & \multicolumn{6}{|c|}{ Proportion of respondents } \\
\hline & $\begin{array}{c}\text { Overall } \\
(\%)\end{array}$ & $\begin{array}{c}\text { Respirologists } \\
(\%)\end{array}$ & $\begin{array}{c}\text { Radiologists } \\
(\%)\end{array}$ & $\begin{array}{c}\text { Thoracic } \\
\text { surgeons } \\
(\%)\end{array}$ & $\begin{array}{c}\text { Internists } \\
(\%)\end{array}$ & $\begin{array}{c}\text { Comparison } \\
\text { across } \\
\text { specialties } \\
(P \text { value })\end{array}$ \\
\hline \multicolumn{7}{|l|}{ Case 1} \\
\hline Very high probability, & 53 & 35 & 80 & 28 & 63 & $<.0001$ \\
\hline \multicolumn{7}{|l|}{ Case 2} \\
\hline $\begin{array}{l}\text { Intermediate probability, } \\
\text { Medically fit for surgery }\end{array}$ & 71 & 62 & 86 & 54 & 75 & $<.0001$ \\
\hline \multicolumn{7}{|l|}{ Case 3} \\
\hline $\begin{array}{l}\text { Very low probability, } \\
\text { Medically fit for surgery }\end{array}$ & 28 & 23 & 31 & 38 & 27 & .14 \\
\hline \multicolumn{7}{|l|}{ Case 4} \\
\hline $\begin{array}{l}\text { Very high probability, } \\
\text { Medically unfit for surgery }\end{array}$ & 25 & 17 & 25 & 38 & 33 & .003 \\
\hline \multicolumn{7}{|l|}{ Case 5} \\
\hline $\begin{array}{l}\text { Intermediate probability, } \\
\text { Medically unfit for surgery }\end{array}$ & 56 & 54 & 54 & 68 & 56 & .13 \\
\hline
\end{tabular}

found heterogeneity in the decision to order a biopsy across the specialties in 3 of the 5 cases.

Table 3 summarizes the management of patients in whom no biopsy would have been ordered. Heterogeneity in management strategies was found for cases 2,4 , and 5 . In these cases, aside from "surgical resection," "radiologic follow-up," and "no additional investigation or treatment," the respondents often stated other options. For case 2 (intermediate probability of malignancy if a medically fit patient), no clear pattern of other options was apparent. For case 4 (very high probability of malignancy in an unfit patient), discussion with the patient followed by best supportive care was the most often mentioned. For case 5 (intermediate probability of malignancy in an unfit patient), referral for radiation therapy was the strategy selected most often. Among the other options, positron emission tomography (PET) scanning was rarely elicited. Overall, PET scanning would have been ordered by less than $2 \%$ of the respondents in each of the 5 scenarios.

\section{Predictors of the Use of TNB}

The results of the regression analysis are presented in Table 4. The pretest probability of malignancy was the most powerful predictor of the use of TNB. Patients with intermediate probability of malignancy were 5 times more likely to be offered TNB than patients with low probability of malignancy $(P<.0001)$. Patients with very high probability of malignancy were less likely to be offered TNB than patients with intermediate probability of malignancy. However, this difference was not statistically significant. The only other significant predictors were patient's operability, specialty (pulmonologists and thoracic surgeons being 35\% to $50 \%$ less likely to order a TNB than radiologists), and respondent's gender.

\section{Discussion}

The results of this survey should be interpreted in light of the guidelines issued by the American Thoracic Society. ${ }^{6}$ The primary indication of TNB is to determine the etiology of solitary or multiple lung nodules, particularly when infection or cancer is suspected. According to the same guidelines, situations in which biopsy results, whether negative or positive, would have no effect on the patient's management or prognosis represent arguments against TNB.

In our survey-based study, we found that physicians tended to overestimate the pretest probability of cancer. This situation may partly explain the perceived indication of TNB in case 3 (ie, the patient with the nodule associated to a very low probability of malignancy), as this nodule was often considered by the respondents as of intermediate probability. Similarly, this situation may partly explain the referral for radiation therapy even though the diagnosis of malignancy was not proven in case 5 (ie, the patient with the nodule associated to an intermediate probability of malignancy), as this nodule was often considered by the respondents as of very high probability of malignancy. On the other hand, TNB was overused in case 1 (ie, the medically fit patient with a nodule associated to a very high probability of malignancy), when the result was unlikely to affect the management of the patient. This interpretation of the results assumes that the pretest probability estimated from Swensen's model is correct. An alternative interpretation would be that clinicians are more accurate in their current pretest 
TABLE 3. Management of the patients in whom no biopsy would have been ordered

\begin{tabular}{|c|c|c|c|c|c|c|}
\hline \multirow[b]{2}{*}{ Clinical scenario } & \multirow[b]{2}{*}{$\begin{array}{c}\text { Proportion of } \\
\text { patients not } \\
\text { biopsiedt }(\%)\end{array}$} & \multicolumn{5}{|c|}{ Management options* } \\
\hline & & $\begin{array}{c}\text { Surgical } \\
\text { resection (\%) }\end{array}$ & $\begin{array}{l}\text { Radio- } \\
\text { logical } \\
\text { follow-up } \\
(\%)\end{array}$ & $\begin{array}{c}\text { No additional } \\
\text { investigation } \\
\text { or treatment } \\
(\%)\end{array}$ & $\begin{array}{c}\text { Other } \\
\text { option } \\
(\%) \\
\end{array}$ & $\begin{array}{c}\text { Comparison } \\
\text { across } \\
\text { specialties } \\
(P \text { value }) \\
\end{array}$ \\
\hline \multicolumn{7}{|l|}{ Case 1} \\
\hline $\begin{array}{l}\text { Very high probability, } \\
\text { Medically fit for surgery }\end{array}$ & 47 & 92 & 0 & 0 & 8 & .39 \\
\hline \multicolumn{7}{|l|}{ Case 2} \\
\hline $\begin{array}{l}\text { Intermediate probability, } \\
\text { Medically fit for surgery }\end{array}$ & 29 & 64 & 17 & 0 & 18 & $<.0001$ \\
\hline \multicolumn{7}{|l|}{ Case 3} \\
\hline $\begin{array}{l}\text { Very low probability, } \\
\text { Medically fit for surgery }\end{array}$ & 72 & 5 & 86 & 0 & 8 & .09 \\
\hline \multicolumn{7}{|l|}{ Case 4} \\
\hline $\begin{array}{l}\text { Very high probability, } \\
\text { Medically unfit for surgery }\end{array}$ & 74 & 4 & 41 & 39 & 15 & .24 \\
\hline \multicolumn{7}{|l|}{ Case 5} \\
\hline $\begin{array}{l}\text { Intermediate probability, } \\
\text { Medically unfit for surgery }\end{array}$ & 43 & 4 & 60 & 15 & 19 & .45 \\
\hline
\end{tabular}

*The sum of the proportions may not add up to $100 \%$ as a small proportion of physicians $(<1.5 \%)$ did not respond to Question 2 .

†The sum of the proportion of patients not biopsied (Table 4) and those biopsied (Table 3) may not add up to $100 \%$ as a small proportion of physicians $(<1.0 \%)$ did not respond to Question 1 .

probability estimates than Swensen's model. Our computation of the pretest probabilities of malignancy from other prediction models ${ }^{3,4}$ demonstrated very good agreement in the probabilities, although the models were developed in different settings and in different points in time (data not shown).

From the American Thoracic Society guidelines, the patient most likely to benefit from TNB was case 2, represented by the medically fit patient with a moderate probability $(38 \%)$ of malignancy; $71 \%$ of the respondents would have referred this patient to TNB. Of the other $29 \%$, two thirds would have directly referred the patient to surgical resection.

Whether a patient is medically fit for surgery was a predictor of the use of TNB, but not to the extent we expected. In case 4 , we posed the case of a 68 -year-old woman with a nodule associated to a high probability of malignancy $(83 \%)$. She was medically unfit for surgery because of severe COPD and left ventricular dysfunction. Also, she had already informed her treating physician that she would refuse chest radiotherapy as a treatment should this lesion be proved to be malignant. This patient would have been referred for TNB by $25 \%$ of the respondents. This situation is considered by the American Thoracic Society a contraindication to TNB. ${ }^{6}$ More controversy surrounded case 5 , represented by the medically unfit patient with an intermediate probability nodule. In this case and according to the American Thoracic Society guidelines, TNB could be useful to diagnose cancer in a patient who, because of personal or clinical reasons, is not a candidate for resection of the lesion unless it is definitely malignant. ${ }^{6}$ Clearly, this indication is not widely accepted among physicians, as this individual would have been referred for TNB by $56 \%$ of the respondents. An alternative explanation for this high rate of biopsy in patients who are apparently "unfit for surgery" is that a general consensus may not exist as to how to define "fitness for surgery," especially in the era of limited resection by thoracoscopy.

Do our findings really reflect the use of TNB in Canada? The response rate we obtained $(47 \%)$ is typical of the reply of physicians to mailed surveys. ${ }^{11}$ In their review of 321 distinct mail surveys examining attitudes and behaviors in health care settings published in American journals in 1991, Asch and coworkers ${ }^{11}$ reported that physicians had the lowest mean response rate among all groups examined $(54 \% \pm 17 \%)$. Nonresponse to any survey may be a problem because of the possibility that respondents differ in a meaningful way from nonrespondents, thus biasing the results. However, surveys with low response rates may provide a representative sample of the study population. We attempted to investigate the potential of nonrespondent bias by making a priori predictions on the response rates across specialties and by examining the representation in the survey of physicians from all the regions on the country. Roughly, the response rates met our a priori predictions. Also, all parts of Canada were proportionally represented in the survey. Whether the results of our survey reflect the actual use of TNB by the sample population remains unan- 
TABLE 4. Predictors of the use of transthoracic needle biopsy: results of the regression analysis

\begin{tabular}{|c|c|c|c|c|}
\hline Variable & Parameters & $\begin{array}{c}\text { Proportion } \\
\text { biopsied } \\
(\%)^{*}\end{array}$ & $\begin{array}{c}\text { Odds ratio } \\
\text { (95\% CI) }\end{array}$ & $P$ valuet \\
\hline \multirow[t]{2}{*}{ Gender } & Male & 45 & 1.00 (referent) & - \\
\hline & Female & 55 & $1.57(1.22-2.01)$ & $<.0001$ \\
\hline \multirow[t]{5}{*}{ Site of practice } & Quebec & 43 & 1.00 (referent) & - \\
\hline & Atlantic provinces & 48 & $1.10(0.76-1.60)$ & .61 \\
\hline & Ontario & 51 & $1.32(1.06-1.64)$ & .012 \\
\hline & Prairies & 44 & $0.90(0.68-1.19)$ & .47 \\
\hline & British Columbia & 46 & $1.00(0.75-1.34)$ & .97 \\
\hline \multirow[t]{4}{*}{ Specialty } & Radiologists & 55 & 1.00 (referent) & - \\
\hline & Pulmonologists & 38 & $0.52(0.40-0.69)$ & $<.0001$ \\
\hline & Thoracic surgeons & 46 & $0.65(0.47-0.70)$ & .0091 \\
\hline & Internists & 51 & $0.80(0.57-1.12)$ & .19 \\
\hline \multirow[t]{2}{*}{ Type of hospital } & Non-university-affiliated & 51 & 1.00 (referent) & - \\
\hline & University-affiliated & 44 & $0.83(0.69-1.00)$ & .04 \\
\hline \multirow[t]{2}{*}{ Clinical experience with SPN } & 1-12 patients/year & 50 & 1.00 (referent) & - \\
\hline & $>12$ patients/year & 45 & $0.80(0.64-0.98)$ & .03 \\
\hline \multirow[t]{2}{*}{ Perform TNB themselves } & No & 53 & 1.00 (referent) & - \\
\hline & Yes & 45 & $1.22(0.92-1.61)$ & .17 \\
\hline \multirow[t]{2}{*}{ Patients' fitness to surgery } & No & 41 & 1.00 (referent) & - \\
\hline & Yes & 51 & $1.80(1.48-2.18)$ & $<.0001$ \\
\hline $\begin{array}{l}\text { Clinical experience } \\
\text { (per years in practice) }\end{array}$ & & & $1.01(1.00-1.02)$ & .11 \\
\hline \multirow[t]{5}{*}{ Pretest probability of malignancy $\ddagger$} & Very low & 0 & 0.00 (0.00-infinite) & 1.00 \\
\hline & Low & 28 & 1.00 (referent) & - \\
\hline & Intermediate & 67 & $5.44(3.85-7.69)$ & $<.0001$ \\
\hline & High & 68 & $7.08(5.11-9.81)$ & $<.0001$ \\
\hline & Very high & 48 & $3.48(2.66-4.60)$ & $<.0001$ \\
\hline
\end{tabular}

*Proportion of patients on whom a TNB would have been ordered.

tGiven the large number of comparisons, the results were considered statistically significant when $P$ was $<.01$.

fFrom the estimate of the physicians (not the probability of malignancy derived from Swensen's model).

swered since the respondents were presented hypothetical clinical scenarios.

We acknowledge that the inclusion of flexible bronchoscopy as a routine diagnostic procedure in all of our 5 scenarios may be controversial. ${ }^{14,15}$ All 5 bronchoscopies were nondiagnostic. We made this decision on purpose. This survey was not designed to examine whether clinicians would select flexible bronchoscopy or TNB in the management of patients with solitary pulmonary nodules after the initial clinical and radiologic evaluation. By incorporating a negative bronchoscopy in each scenario, we wanted to isolate the option of TNB as the next step in management. In doing so, the bronchoscopy slightly modified the probability of malignancy, even if it was nondiagnostic. The authors of most studies of the diagnostic accuracy of bronchoscopy reported their results in terms of "diagnostic yield" in malignant nodules. ${ }^{16}$ The most recent study by Baaklini ${ }^{17}$ included patients with both malignant and benign solitary nodules. From their data, we computed that the likelihood ratio (which indicates by how much a given test result raises or lowers the pretest probability of the target disorder ${ }^{18}$ ) associated to a nondiagnostic bronchoscopy in patients with solitary nodules smaller than $3 \mathrm{~cm}$ is 0.9 . This likelihood ratio merely reduces the probability of malignancy for each scenario to $73 \%, 36 \%,<2 \%, 82 \%$, and $34 \%$, respectively.

Several reports have questioned the current use of TNB. ${ }^{8,9}$ In a retrospective study of 113 patients who underwent 117 biopsies between 1991 and 1996, the diagnostic accuracy of the procedure was high (sensitivity: $85 \%$; specificity: $100 \%) .{ }^{9}$ Of the biopsies, $54.7 \%$ were associated with a iatrogenic pneumothorax, about half of them necessitating hospitalization for either observation or chest tube drainage. Nevertheless, for most patients, the result of the procedure did little to modify the course of surgical management. The authors recommended that TNB should be limited to patients who are medically unfit and could not tolerate surgery, to patients who refuse surgery, and to patients with advanced disease. In a different setting, the same conclusions were reached by independent investigators. ${ }^{8}$ In this study, Larscheid and coworkers retrospectively reviewed the charts of 130 consecutive patients who had undergone TNB. The sensitivity of TNB for the detection of malignancy was $74 \%$ and its specificity was $100 \%$. The authors concluded that the information gained from TNB rarely 
resulted in a change in their clinical management and that TNB is most useful for diagnosing pulmonary nodules that are likely to be malignant in patients who are not candidates for other surgical procedures.

The recent introduction of positron emission tomography (PET) scanning further complicates the integration of TNB in the diagnostic algorithm of localized pulmonary lesions. Several studies have reported high sensitivity and specificity of this new technology in the detection of malignant solitary pulmonary nodules. ${ }^{19}$ A recent head-to-head comparison between TNB and PET scanning ${ }^{20}$ suggested that PET imaging of the lung is as accurate as TNB in the evaluation of lung lesions suspected to be malignant. For methodologic reasons, this study did not meet, however, the inclusion criteria of our meta-analysis. ${ }^{7}$ PET scanning was rarely elicited by our respondents as a diagnostic option in the management of the patients we presented. This situation may reflect the fact that, as of January 1, 2001, only 7 PET centers were in function in Canada.

Finally, the role of TNB in the investigation of solitary pulmonary nodules may increase if induction chemotherapy in early-stage, non-small cell lung cancer proves effective in improving survival. ${ }^{21}$ In the meantime, the indications of TNB must be based on the estimate of pretest probability of malignancy and the likelihood that the test result will affect the management of the patient. The recent interest in screening of lung cancer by low-dose computed tomography launched by the Early Lung Cancer Action Project ${ }^{22}$ will likely result in the finding of a large number of pulmonary nodules for which TNB is seldom truly indicated.

We thank the respondents to the survey for their time, particularly those who provided useful comments.

\section{References}

1. Swensen SJ, Silverstein MD, Ilstrup DM, Schleck CD, Edell ES. The probability of malignancy in solitary pulmonary nodules: application to small radiologically indeterminate nodules. Arch Intern Med. 1997; 157:849-55.

2. Lillington GA. Management of solitary pulmonary nodules. Dis Month. 1991;37:271-318.

3. Cummings SR, Lillington GA, Richard RJ. Estimating the probability of malignancy in solitary pulmonary nodules: a Bayesian approach. Am Rev Respir Dis. 1986;134:449-52.

4. Gurney JW. Determining the likelihood of malignancy in solitary pulmonary nodules with Bayesian analysis. Part I. Theory. Radiology. 1993;186:405-13.

5. Nordenström B. A new technique for transthoracic biopsy of lung changes. Br J Radiol. 1965;38:550-3.

6. Sokolowski JW, Burgher LW, Jones FL, for the American Thoracic Society. Guidelines for percutaneous transthoracic needle biopsy. Am Rev Respir Dis. 1989;140:255-6.

7. Lacasse Y, Wong E, Guyatt GH, Cook DJ. Transthoracic needle aspiration biopsy for the diagnosis of localized pulmonary lesions: a meta-analysis. Thorax. 1999;54:884-93.

8. Larscheid RC, Thorpe PE, Scott WJ. Percutaneous transthoracic needle aspiration biopsy: a comprehensive review of its current role in the diagnosis and treatment of lung tumors. Chest. 1998;114:704-9.

9. Odell MJ, Reid KR. Does percutaneous fine needle aspiration biopsy aid in the diagnosis and surgical management of lung masses? Can J Surg. 1999;42:297-301.

10. Dillman DA. Mail and telephone surveys: the total design method. New York: John Wiley; 1978.

11. Asch DA, Jedrziewski MK, Chirtakis NA. Response rates to mail surveys published in medical journals. J Clin Epidemiol. 1997;50: 1129-36.

12. Liang KY, Zeger SL. Longitudinal data analysis using generalized linear models. Biometrika. 1986;73:13-22.

13. Cummings SR, Lillington GA, Richard RJ. Managing solitary pulmonary nodules: the choice of strategy is a "close call." Am Rev Respir Dis. 1986;134:453-60.

14. American Thoracic Society. Pretreatment evaluation of non-small-cell lung cancer. Am J Respir Crit Care Med. 1997;156:320-32.

15. Ost D, Fein A. Evaluation and management of the solitary pulmonary nodule. Am J Respir Crit Care Med. 2000;162:782-7.

16. Arroliga AC, Matthay RA. The role of bronchoscopy in lung cancer. Clin Chest Med. 1993;14:87-98.

17. Baaklini WA, Reinoso MA, Gorin AB, Sharafkaneh A, Manian P. Diagnostic yield of fiberoptic bronchoscopy in evaluating solitary pulmonary nodules. Chest. 2001;117:1049-54.

18. Sackett DL, Haynes RB, Guyatt GH, Tugwell P. Clinical epidemiology: a basic science for clinical medicine. 2nd ed. Boston: Little \& Brown; 1991.

19. Gould MK, Maclean CC, Kuschner WG, Rydzak CE, Owens DK. Accuracy of positron emission tomography for diagnosis of pulmonary nodules and mass lesions: a meta-analysis. JAMA. 2001;285:914-24.

20. Dewan NA, Reeb SD, Gupta NC, Gobar LS, Scott WJ. PET-FDG imaging and transthoracic needle lung aspiration biopsy in the evaluation of pulmonary lesions: a comparative risk-benefit analysis. Chest. 1995;108:441-6.

21. Manegold C. Chemotherapy in stage I/II NSCLC and projects of the EORTC-Lung Cancer Group for Early Lung Cancer. Lung Cancer. 2001;34(Suppl 3):S53-8.

22. Henschke CI, McCauley DI, Yankelevitz DF, Naidich DP, McGuinness G, Miettinen OS, et al. Early Lung Cancer Action Project: overall design and findings from baseline screening. Lancet. 1999;354:99-105.

\section{Appendix}

\section{Clinical Scenarios Presented to the Survey Respondents}

PAtiEnT 1. You are referred a 70-year-old man, ex-mechanic, for the investigation of a solitary pulmonary nodule that was discovered incidentally on a chest radiograph. He has no medical or surgical history. He has a smoking history of 50 pack-years. He is asymptomatic. The chest radiograph shows a 2 -cm left upper lobe nodule. The chest CT scan confirms the presence of a unique 2.0-cm, spiculated, noncalcified lesion in the left upper lobe. There is no mediastinal adenopathy and the rest of the pulmonary parenchyma is normal. In retrospect, on a chest radiograph done a year before, you can visualize this lesion and it has definitely enlarged. The bronchoscopy, blood work (including alkaline phosphatase), and pulmonary function tests are normal. The abdominal ultrasound is also normal. There are no contraindications to surgery.

PAtiEnt 2. A 57-year-old farmer, ex-smoker of 20 pack-years, is referred to you for the investigation of a pulmonary nodule discovered on a routine chest radiograph. He has no known medical problems and he is asymptomatic. The chest radiograph shows a 2-cm nodule in the apical segment of the right upper lobe. There is no prior chest radiograph available. The chest CT scan confirms the presence of this well-defined, noncalcified lesion. The rest of the pulmonary parenchyma is normal and there is no mediastinal adenopathy. The bronchoscopy is normal and the cytologic examination of bronchial secretions does not reveal any malignant cells. His pulmonary function tests are normal. 
PAtient 3. A 35-year-old man is referred to you for the evaluation of a pulmonary nodule found on a routine chest radiograph. His medical history is unremarkable and he has never smoked. There is no history of tuberculous contact and he is asymptomatic. His chest radiograph shows a $1-\mathrm{cm}$ nodule in the right lower lobe. The chest CT scan confirms the presence of a solitary, smooth, noncalcified, $1.2-\mathrm{cm}$ nodule in the right lower lobe. The rest of the pulmonary parenchyma is normal. No prior chest radiograph is available. A bronchoscopy has already been done by the referring physician and was normal.

PAtiEnt 4. You are referred a 68-year-old woman for the assessment of a solitary pulmonary nodule. She has documented chronic obstructive pulmonary disease and severe coronary artery disease. She stopped smoking 8 years ago. A chest radiograph done in the follow-up of her chronic lung disease shows a $3-\mathrm{cm}$ lesion in the left lower lobe. This lesion was absent on a radiograph done 2 years earlier. The chest CT scan confirms the presence of this unique $3.1-\mathrm{cm}$ peripheral lesion with indistinct margins. There is no mediastinal lymphadenopathy. The bronchoscopy is normal and the cytologic examination of bronchial secretions does not reveal any malignant cells. Her best $\mathrm{FEV}_{1}$ [forced expiratory volume in 1 secone] is $30 \%$ of predicted and her left ventricular ejection fraction is $25 \%$. The patient has already informed you that she would refuse chest radiotherapy as a treatment should this lesion be proved to be malignant.
PAtient 5. You see a 72-year-old woman for an abnormal chest radiograph. She has diabetes complicated by nephropathy and peripheral vascular disease. She is also known to have severe ischemic heart disease. She has been smoking since her youth. Her $\mathrm{FEV}_{1}$ is $800 \mathrm{~mL}$ ( $40 \%$ of predicted). Her chest radiograph shows a dense 2-cm nodular opacity in the right lower lobe and some cicatricial markings in the upper lobes. The chest CT scan confirms the presence of this lesion and signs of a previous granulomatosis. There is no mediastinal adenopathy. The bronchoscopy is normal and the cytologic examination of bronchial secretions does not show any malignant cells. There is no prior chest radiograph available for comparison.

Following each scenario, the physicians were asked the same 3 questions:

1. Given this clinical situation, in your current practice, would you order a transthoracic needle biopsy for this patient? If yes, go to question 3; if no, go to question 2 .

2. What would be your next step in the investigation of this patient? A, No additional investigation; B, surgical resection; $\mathrm{C}$, radiologic follow-up; D, other (specify).

3. What would be your best estimate of the probability that this patient's nodule is malignant? (This question was followed by a $100-\mathrm{mm}$ analog scale. The physicians were asked to mark the scale with a vertical line corresponding to their estimate.) 